\title{
Randomised trial of nutrition for preterm infants after discharge
}

\author{
A Lucas, N J Bishop, F J King, T J Cole
}

\begin{abstract}
In a randomised double blind trial, the effect on growth and clinical status of a nutrient enriched 'post-discharge' milk formula versus a standard term formula, was compared in $\mathbf{3 2}$ exclusively bottle fed preterm infants. The formulas were used as the sole milk intake up to a postnatal age of 9 months.

Significant increases in linear growth and weight gain were observed in the infants who received the enriched diet. There were no differences in vomiting, posseting, or bowel habit between the groups. Formula volumes ingested were similar between diet groups, indicating that the difference in formula composition did not affect the infants' regulation of intake.
\end{abstract}

These preliminary data suggest that there is a role for specially designed formulas for preterm infants after discharge from hospital.

There has been increasing recognition that preterm infants have special nutrient needs. ${ }^{1-3}$ Somatic growth, brain growth, and overall nutrient accretion rates in the third trimester substantially exceed those of the infant born at term. ${ }^{4}$ Premature delivery interrupts these processes, and the preterm infant begins postnatal life with comparatively low body stores, particularly of fat, bone minerals, trace metals, and some vitamins. Modern dietary regimens, for instance those employing formulas that have been designed to meet the special increased needs of preterm infants, may confer major benefits for long term growth and developmental attainment in early childhood. ${ }^{5-7}$

The focus of attention in this field, however, has been almost exclusively on hospital based nutritional management. Yet preterm infants are frequently discharged home at a body weight of $1800-2000 \mathrm{~g}$, little over half that of a newborn full term baby. It is not uncommon for both length and weight to be below the 3rd centile at this time. Moreover, unpublished data from our multicentre studies show that, as a population, preterm infants are still growth retarded at 9 and 18 months.

Despite the intensive nutritional management provided during hospitalisation, these infants are discharged home on diets suitable for healthy term babies when they have frequently fulfilled the most stringent criteria for failure to thrive. It seems reasonable to speculate that babies born preterm would continue to benefit from special nutritional attention for the early months after discharge from hospital and possibly throughout infancy.
We have therefore undertaken a randomised, double blind prospective study of the effects on growth and development of a specially designed enriched 'post-discharge' formula, compared with the currently available term formula diet, in a group of preterm infants whose mothers had elected to bottle feed. Our findings on growth, formula intake, and feed tolerance up to 9 months post-term are reported here.

\section{Subjects and methods}

We recruited 32 preterm infants before discharge home after they had received neonatal intensive care. These infants weighed less than $1850 \mathrm{~g}$ at birth. The criteria for inclusion were that they had been formula fed rather than breast milk fed during the hospital stay, were free of congenital malformations and diseases likely to influence growth and neurodevelopment, weighed less than $3 \mathrm{~kg}$ at the time of entry to the study, and were aged less than 100 days. After informed parental consent had been obtained, infants were randomised to receive either a standard 'term' formula (Farley's Oster Milk, Crookes Health Care Ltd), or a specially designed 'follow-on preterm formula' (Farley's Premcare, manufactured for us by Crookes Health Care Ltd; see table 1 for compositional details), both in ready to feed form. Before

Table 1 Composition of nutrient enriched post-discharge milk formula

\begin{tabular}{|c|c|c|}
\hline & Per $100 \mathrm{ml}$ & Per 100 kcalt \\
\hline Protein $(\mathrm{g})$ & $1 \cdot 85^{*}$ & $2 \cdot 6$ \\
\hline Fat $(g)$ & $4 \cdot 0$ & $5 \cdot 5$ \\
\hline Carbohydrate (g) & $7 \cdot 3$ & $10 \cdot 1$ \\
\hline Calcium (mg) & 70 & 97 \\
\hline Chloride (mg) & 45 & 63 \\
\hline Copper $(\mu \mathrm{g})$ & 57 & 80 \\
\hline Iodine $(\mu \mathrm{g})$ & $4 \cdot 5$ & $6 \cdot 3$ \\
\hline Iron $(\mu \mathrm{g})$ & 650 & 900 \\
\hline Magnesium (mg) & $5 \cdot 2$ & $7 \cdot 2$ \\
\hline Manganese $(\mu \mathrm{g})$ & 5 & 7 \\
\hline Phosphorus (mg) & 35 & 49 \\
\hline Potassium (mg) & 78 & 110 \\
\hline Sodium (mg) & 22 & 31 \\
\hline Zinc $(\mu \mathrm{g})$ & 600 & 840 \\
\hline Vitamin A (ug) & 100 & 139 \\
\hline Vitamin B-1 $(\mu \mathrm{g})$ & 95 & 132 \\
\hline Vitamin B-2 $(\mu \mathrm{g})$ & 100 & 139 \\
\hline Vitamin B-6 $(\mu \mathrm{g})$ & 80 & 111 \\
\hline Vitamin B-12 (ug) & $0 \cdot 2$ & 0.3 \\
\hline Biotin $(\mu \mathrm{g})$ & $1 \cdot 1$ & 1.5 \\
\hline Folate $(\mu \mathrm{g})$ & 25 & 35 \\
\hline Niacin $(\boldsymbol{\mu g})$ & 1000 & 1388 \\
\hline Pantothenate $(\mu \mathrm{g})$ & 400 & 555 \\
\hline Vitamin C (mg) & 15 & 21 \\
\hline Vitamin D $(\mu \mathrm{g})$ & $1 \cdot 3$ & 1.8 \\
\hline Vitamin E (mg) & 1.5 & $2 \cdot 1$ \\
\hline Vitamin $\mathbf{K}(\mu \mathrm{g})$ & 6.0 & $8 \cdot 3$ \\
\hline Taurine (mg) & $5 \cdot 1$ & $7 \cdot 1$ \\
\hline Carnitine (mg) & $1 \cdot 1$ & 1.5 \\
\hline Energy (kcal + ) & 72 & 100 \\
\hline Inositol (mg) & $3 \cdot 2$ & $4 \cdot 4$ \\
\hline Choline (mg) & $5 \cdot 1$ & $7 \cdot 0$ \\
\hline
\end{tabular}

*Casein:whey ratio 40:60. $+100 \mathrm{kcal}=418 \mathrm{~kJ}$. Downhams Lane, Cambridge CB4 1XJ. Accepted 4 November 1991
Unit and University Paediatrics, Cambridge N J Bishop F J King Correspondence to 
Table 2 Demographic, clinical, and anthropometric characteristics of study groups (data are means $(S D)$ unless otherwise stated)

\begin{tabular}{lll}
\hline & $\begin{array}{l}\text { Standard term } \\
\text { formula }(n=15)\end{array}$ & $\begin{array}{l}\text { Follow-on preterm } \\
\text { formula }(n=16)\end{array}$ \\
\hline $\begin{array}{l}\text { Gestation (weeks) } \\
\text { Birth weight (g) }\end{array}$ & $31 \cdot 7(1 \cdot 9)$ & $30 \cdot 7(1 \cdot 7)$ \\
Males:females & $1436(227)$ & $1513(173)$ \\
No of infants ventilated & $8: 7$ & $7: 9$ \\
>1 day & 6 & 8 \\
>7 days & 0 & 1 \\
Median No days on intravenous nutrition & $4(2-8)$ & $5(3-10)$ \\
(interquartile range) & $37(2)$ & $37(2)$ \\
Postmenstrual age at trial entry (weeks) & $2383(221)$ & $2401(343)$ \\
Anthropometry at trial entry: & $46 \cdot 0(1 \cdot 4)$ & $46 \cdot 3(2 \cdot 2)$ \\
$\quad$ Weight (g) & $33 \cdot 3(1 \cdot 0)$ & $33 \cdot 2(1 \cdot 2)$ \\
Length (cm) & $5 \cdot 0(1 \cdot 1)$ & $4 \cdot 7(1 \cdot 1)$ \\
Head circumference (cm) & $4 \cdot 5(0 \cdot 6)$ & $4 \cdot 8(1 \cdot 1)$ \\
Triceps skinfold (mm) & & \\
Subscapular skinfold (mm) & & \\
\hline
\end{tabular}

${ }^{*}$ Partial or complete.

Table 3 Milk volume intake at corrected postnatal ages. Data are mean (SD) in litres

\begin{tabular}{llll}
\hline & $0-3$ Months & $>3-6$ Months & $>6-9$ months \\
\hline Standard term formula $(n=15)$ & $73.4(13 \cdot 5)$ & $69.4(15 \cdot 4)$ & $75 \cdot 1(32 \cdot 0)$ \\
Follow-on formula $(\mathrm{n}=16)$ & $71.6(14.9)$ & $69.8(12 \cdot 2)$ & $65 \cdot 6(23.9)$ \\
\hline
\end{tabular}

randomisation, all the infants had been in the Rosie Maternity Hospital neonatal intensive care unit, and had had intensive data collection undertaken from birth.

The infants were started on the assigned diet while still in hospital; clinical data, together with mean postmenstrual age and anthropometric data at trial entry are given in table 2 .

After discharge from hospital, a research nurse (FJK) visited each infant fortnightly to record anthropometry and clinical data. Weight was measured to the nearest $10 \mathrm{~g}$ using a Sartorius MP electronic balance; length was measured using a horizontal stadiometer to the next succeeding $1 \mathrm{~mm}$; occipitofrontal circumference was measured to the next succeeding $1 \mathrm{~mm}$ using a paper tape measure; skinfold thicknesses-triceps and subscapular-were measured to the nearest $0.1 \mathrm{~mm}$ using Harpenden calipers.

At each visit, further supplies of milk were delivered. Boxes were weighed before delivery, and the parents instructed to replace capped empty or partially emptied bottles in the boxes after use. Volume intake over the two week period was calculated by subtracting the weights of used or partly used boxes of milk from their full weights (see table 3 for volume intake details).

The infants received the assigned diet, either as a sole source of nutrition or in conjunction with other foods until 9 months corrected postnatal age.

Student's $t$ test and $\chi^{2}$ analyses were used to compare the two groups at specific corrected postnatal ages.

Longitudinal growth performance was compared in the two groups by multiple linear regression analysis using successive attained anthropometric measurements as dependent variables with previous measurements and diet type as independent factors on a within subject basis, using a quadratic fit.

Based on previous follow up data on preterm infants, ${ }^{5}$ sample size was calculated to detect a $10 \%$ difference in weight gain to 9 months postterm at $5 \%$ significance and $80 \%$ power.

\section{Results}

The two groups of infants were closely matched in terms of their birth weight, gestation, and sex ratio. Postmenstrual age and weight at point of entry to the study - that is, when the transfer to the post-discharge diet was made-were also very similar for each group (see table 2 ). One infant randomly assigned to the standard formula became unwell before discharge and required surgery at another hospital. This baby could not be studied in the postnatal period, leaving 15 subjects in this group.

\section{GROWTH}

The growth performance of the two diet groups is shown for both sexes plotted on combined centiles in the figure (based on Gardner-Pearson growth charts). Differences between the diet groups are apparent on visual inspection of the charts. At 37 weeks' postmenstrual age, on
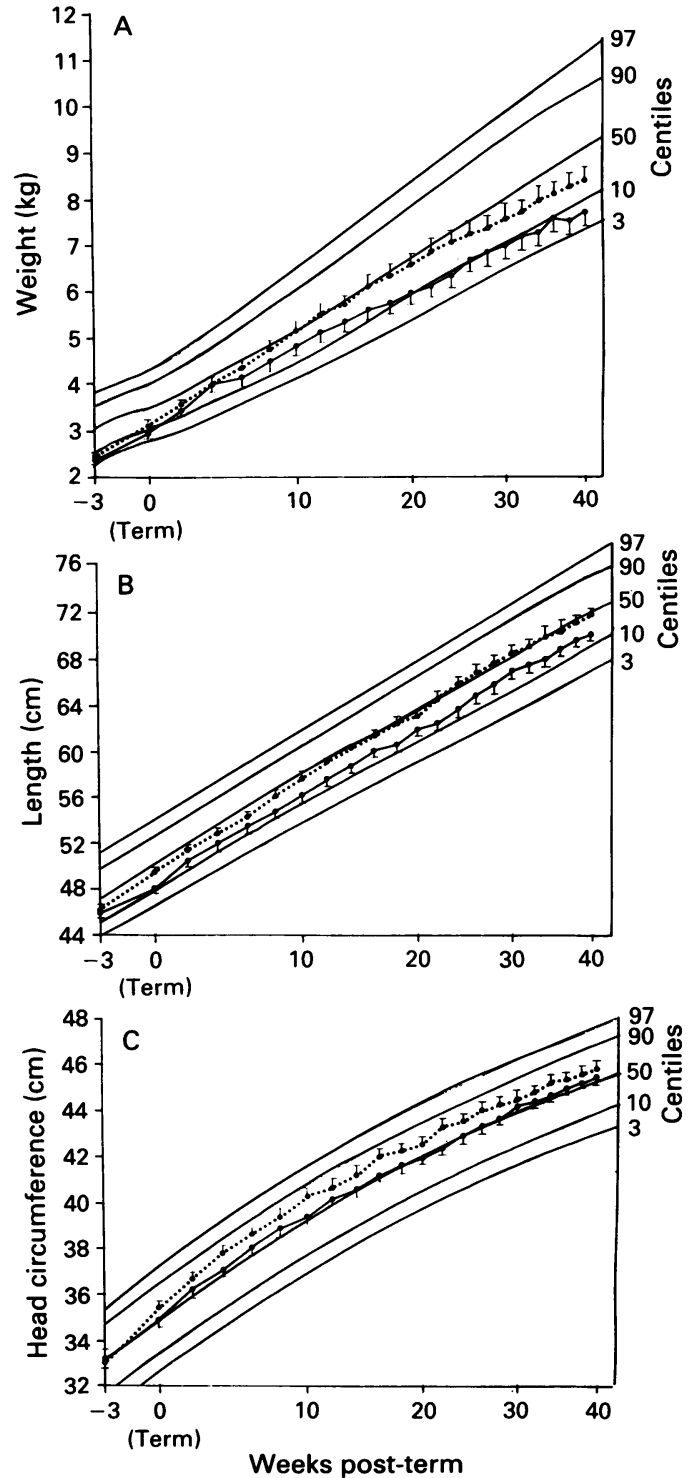

Longitudinal data (means $(S E)$ ) for $(A)$ body weight, $(B)$ body length, and $(C)$ head circumference in babies fed $a$ standard formula (solid line) versus those fed the follow-on formula (dotted line) from recruitment (mean three weeks' formula (dotted line) from recruitment (mean three weeks'
preterm) to 40 weeks post-term. Data are for both sexes combined; centiles derived from Gardner-Pearson chart (published by Castlemead, UK). 
entry to the study, body weight lay between the 3rd and 10th centiles. By 9 months this was still the case for infants fed on standard formula, but those fed the nutrient enriched formula lay close to the 25th centile. Body length at 37 weeks' postmenstrual age lay close to the 25 th centile in both groups. This was still so at 9 months for the infants fed the standard formula but those fed the enriched formula remained close to the 50th centile from 4 months post-term onwards. Significant differences between feed groups in body weight and length were seen at some individual time periods. However, a within subject analysis to examine longitudinal growth rate, using a quadratic fit, showed significant increases in weight gain $(p<0.005)$ and linear growth $(p<0.01)$ in the group on a nutrient enriched diet compared with those on the standard formula throughout the whole 9 month study period. While head growth data indicate a divergence between diet groups, most noticeable in the 2-6 month period, the difference in head growth rate between groups did not reach significance. Skinfold thicknesses (triceps, subscapular) did not differ significantly between the diet groups.

\section{FEED INTAKE AND WEANING}

During the periods $0-3$ months and $>3-6$ months post-term, formula intake was the same in the two groups (see table 3). The trend towards reduced formula intake in the group fed the nutrient enriched milk at $>6-9$ months was not significant. In addition, there was no significant difference in the time of introduction of weaning foods: mean (SD) corrected age 10.7 (4.5) weeks in the standard formula group and $12.6(4 \cdot 2)$ weeks in the follow-on preterm formula group.

\section{FEED TOLERANCE}

We collected data on the number of vomits, possets, and bowel motions for each infant on a day to day basis, and also the number of episodes of colic, the stool consistency and its volume (using charts developed for studies of gastrointestinal upset in UK and Gambian children by the MRC Dunn Nutrition Unit). ${ }^{8}$

Table 4 Feed tolerance. Data are median (interquartile range)

\begin{tabular}{llll}
\hline & Vomits/day & Possets/day & Colic episodes/2 weeks \\
\hline Standard term formula $(n=15)$ & $0 \cdot 9(0 \cdot 1-1 \cdot 8)$ & $1 \cdot 7(1 \cdot 1-4 \cdot 2)$ & $1(0-3)$ \\
Follow-on formula $(n=16)$ & $0 \cdot 6(0 \cdot 2-1 \cdot 3)$ & $2 \cdot 3(1 \cdot 0-5 \cdot 5)$ & $1(0-4)$ \\
\hline
\end{tabular}

Table 5 Stool data at corrected postnatal ages. Data are mean (SE)

\begin{tabular}{|c|c|c|c|}
\hline & 0-3 Months & $>3-6$ Months & $>6-9$ Months \\
\hline $\begin{array}{l}\text { Standard term formula }(n=15) \\
\text { No/day } \\
\text { Size* } \\
\text { Consistencyt }\end{array}$ & $\begin{array}{l}2.0(0.18) \\
3.1(0.15) \\
2.9(0.11)\end{array}$ & $\begin{array}{l}1.5(0.06) \\
3.4(0.07) \\
2.5(0.14)\end{array}$ & $\begin{array}{l}1 \cdot 8(0.08) \\
3 \cdot 3(0.08) \\
2 \cdot 4(0.07)\end{array}$ \\
\hline $\begin{array}{l}\text { Follow-on formula }(n=16) \\
\text { No/day } \\
\text { Size* } \\
\text { Consistencyt }\end{array}$ & $\begin{array}{l}2 \cdot 2(0.24) \\
3.3(0.14) \\
2 \cdot 8(0.13)\end{array}$ & $\begin{array}{l}1.9(0.14) \\
3.4(0.15) \\
2.3(0.16)\end{array}$ & $\begin{array}{l}2.0(0.31) \\
3.6(0.17) \\
2.5(0.09)\end{array}$ \\
\hline
\end{tabular}

*Size graded (approximately) by mother using comparison charts: $1=1 \mathrm{~g}, 2=2.5 \mathrm{~g}, 3=5 \mathrm{~g}, 4=10 \mathrm{~g}$,

$5=20 \mathrm{~g}$.
tConsistency graded by mother using comparison charts: $1=$ hard, $2=$ formed soft, 3 =mushy soft, $4=$ runny, $5=$ watery.
There was no difference between the diet groups for any of these factors, although individual variation was large (see tables 4 and $5)$, and there was an overall trend towards larger stool weights in infants receiving the follow-on formula.

\section{Discussion}

In this study infants whose mothers chose to bottle feed were randomly assigned to a special nutrient enriched follow-on preterm formula or to a standard term formula, to be used either alone or in conjunction with weaning foods throughout the first 9 months post-term. During this study period the infants fed on the special formula gained a higher centile for weight, length and head circumference; and for weight and length gain velocities, the advantage for the special formula was significant.

The special follow-on preterm formula was designed to be intermediate in its composition between a standard term formula and a special preterm formula, though in fact its composition falls within the current Department of Health and Social Security, European Society for Gastroenterology and Nutrition, and European Community guidelines for a standard formula. ${ }^{9} 10 \mathrm{An}$ increased energy content of $72 \mathrm{kcal}$ $(302 \mathrm{~kJ}) / 100 \mathrm{ml}$ (an increase on the $68 \mathrm{kcal}$ (286 $\mathrm{kJ} / 100 \mathrm{ml}$ in most standard formulas) was incorporated to promote utilisation of the increased protein intake, while recognising that excessive energy intake might result in unnecessary fat gain. The protein content was set at $1.85 \mathrm{~g} / 100 \mathrm{ml}$, around $20 \%$ higher than in a routine highly adapted formula, in order to promote catch-up growth.

Metabolic bone disease is very common in preterm infants ${ }^{11} 12$ and many leave hospital with undermineralised bones. ${ }^{13}$ The follow-on formula provided a substantially higher calcium and phosphorus content than that found in most standard formulas. Relatively high levels of trace minerals (zinc and copper) were incorporated to attempt to replete the low body stores expected after preterm birth, compounded by the negative balance status observed in this population during the early weeks, ${ }^{14}{ }^{15}$ and specifically to address the concern, expressed by others, that low zinc status in the period after discharge could result in suboptimal growth. ${ }^{16}$ Levels of a number of vitamins have been increased proportional to the projected increased growth rate.

The higher growth rate observed in the infants fed the special formula was likely to have related to the generally higher nutrient intake, though the high calcium and phosphorus intake could have been especially important for the increase in linear growth. We and others have shown that deficient bone mineral intake in infants born preterm is associated with reduced linear growth in the neonatal period ${ }^{17} 18$ and with reduced attained length at 18 months. ${ }^{7}$ This aspect of the study will be explored further when we report the results of the sequential bone mineral content measurements made concomitantly. The increases in weight and length (together with a trend towards increased head 
Table 6 Skinfold thickness and diet after discharge at corrected postnatal ages. Data are mean $(S E)$ in $\mathrm{mm}$

\begin{tabular}{llll}
\hline & $0-3$ Months & $>3-6$ Months & $>6-9$ Months \\
\hline Standard term formula & $7 \cdot 7(0 \cdot 3)$ & $8 \cdot 9(0 \cdot 6)$ & $8 \cdot 7(0 \cdot 7)$ \\
$\quad$ Triceps & $7 \cdot 4(0 \cdot 6)$ & $7 \cdot 2(0 \cdot 6)$ & $6 \cdot 9(0 \cdot 7)$ \\
Subscapular & $7 \cdot 9(0 \cdot 4)$ & $8 \cdot 6(0 \cdot 4)$ & $9 \cdot 2(0 \cdot 4)$ \\
Follow-on formula & $6 \cdot 8(0 \cdot 3)$ & $6 \cdot 8(0 \cdot 4)$ & $6 \cdot 7(0 \cdot 4)$ \\
Triceps & &
\end{tabular}

growth) without a corresponding increase in skinfold thickness (table 6) indicates that the improved growth in infants fed the nutrient enriched formula cannot be attributed simply to increased body fatness.

The most important question raised by our data is whether the improved growth after discharge of infants fed on the special formula will be related to improved developmental status and body size at subsequent follow up. We are conducting formal follow up examinations on this cohort with detailed neurodevelopmental testing at 9 and 18 months post-term and the findings will be reported. Our previous studies have indicated that the early weeks may be critical for the nutrition of the preterm baby and that a relatively brief period of dietary manipulation may have a profound influence on developmental scores 18 months later. ${ }^{5}$ The possibility that this 'sensitive' period extends further into infancy, beyond the period of hospitalisation, is a hypothesis that will be tested on this cohort. The investigation we report is a relatively small initial study and targeted to detect differences between groups in short term growth. Only large differences in developmental quotients (albeit of the magnitude observed in our previous nutritional studies) could be detected here. Nevertheless, even if longer term effects could not be shown in this study, the improved growth rate throughout infancy in the babies fed the special formula must be regarded as a potential clinical advantage in terms of improving their general nutritional status.

It was interesting that the special formula group had the same volume of intake as the infants fed the normal formula during the first 6 months. Some previous investigators ${ }^{19} 20$ have suggested that babies regulate their milk intake in relation to the energy or nutrient density. Yet we found no down regulation of volume of intake in the special formula group, so that these babies achieved increased nutrient intake. Our data add to the broader debate on the issue of appetite regulation in the infant.
Premature babies in this study achieved their better growth performance after discharge without an increase in gastrointestinal disturbance or other observed problems. These data support the concept of using specially designed formulas throughout the first 9 months postterm for bottle fed babies born preterm. Our data do not address breast feeding in this group; this is an area for further investigation.

We acknowledge Farley Health Products for financial support and Mrs Evelyn Smith for preparation of the manuscript.

1 Lucas A, Gore SM, Cole TJ, et al. Multicentre trial on the feeding of low birthweight infants: effects of diet on early growth. Arch Dis Child 1984;59:722-30.

2 Ziegler EE, Biga RL, Fomon SJ. Nutritional requirements of the premature infant. In: Suskind RM, ed. Textbook of pediatric nutrition. New York: Raven Press, 1981:29-39.

3 Committee on Nutrition of the Amerian Academy of Pediatrics. Nutritional needs of low birthweight infants. Pediatrics 1977;60:519-30.

4 Ziegler EE, O'Donnell AM, Nelson SE, Fomon SJ. Body composition of the reference fetus. Growth 1976;40:329-41.

5 Lucas A, Morley R, Cole TJ, et al. Early diet in preterm babies and developmental status in infancy. Arch Dis Child 1989;64:1570-8.

6 Lucas A, Morley R, Cole TJ, et al. Early diet in preterm babies and developmental status at 18 months. Lancet 1990;335:1477-81

7 Lucas A, Brooke OG, Baker BA, Bishop N, Morley R. High plasma alkaline phosphatase activity and growth in preterm neonates. Arch Dis Child 1989;64:902-9.

8 Weaver LT, Ewing G, Taylor L. The bowel habit of milk-fed infants. $\mathcal{F}$ Pediatr Gastroenterol Nutr 1988;7:568-71.

9 Department of Health and Social Security. Artificial feeds for the young infants: report of the committee on medical aspects of food policy. (DHSS Report on Health and Social Services No 18.) London: HMSO, 1980.

10 ESPGAN Committee on Nutrition. Interim report 1983. Proceedings of European Society of Gastroenterology and Nutrition. Graz, 1983.

11 Steichen JJ, Gratton TL, Tsang RC. Osteopenia of prematurity: the cause and possible treatment. $\mathcal{F}$ Pediatr maturity: the

12 James JR, Congdon PJ, Truscott J, Horsman A, Arthur R. Osteopenia of prematurity. Arch Dis Child 1986;61:871-6.

13 Cooper PA, Rothberg AD, Pettifor JM. Early follow up of very low birth weight infants after hospital discharge with respect to growth and mineral homeostasis. $\mathcal{F}$ Pediatr Gastroenterol Nutr 1988;7:577-82.

14 Shaw JCL. Trace elements in the fetus and young infant. I. Zinc. Am $\mathcal{F}$ Dis Child 1979;133:1260-8.

15 Donlon J, Tyrala EE. Absorption and retention of copper, zinc, calcium and phosphorus in premature infants. Pediatr Res 1984;18:215.

16 Casey CE, Hambidge KM. Trace minerals. In: Tsang RC, ed. Vitamin and mineral requirements in preterm infants. New York: Dekker, 1985:153-84.

17 Greer FR, McCormick A. Bone growth with low bone mineral content in very low birth weight premature infants. Pediatr Res 1986;20:925-8.

18 Cooper PA, Rothberg AD, Davies VA, Argent AC. Comparative growth and biochemical response of very low birthweight infants fed own mothers milk, a premature infant weight infants fed own mothers milk, a premature infant Garmula, or one of two standard

19 Brooke OG, Kinsey JM. High energy feeding in small for gestation infants. Arch Dis Child 1985;60:42-6.

20 Fomon SJ, Filmer LJ, Jr, Thomas LN, Anderson TA, Nelson SE. Influence of formula concentration on caloric intake and growth of normal infants. Acta Paediatr Scand 1975;64: $172-81$. 